Research article

JMCJMS

\title{
Effect of Lamotrigine on fetal rat brain morphology
}

\author{
Sah N1, Pandit RK², Dhungel S 3
}

Department of Anatomy, BP Koirala Institute of Health Science, Dharan, Nepal

1Department of Anatomy, Janaki Medical College Teaching Hospital, Janakpurdham, Nepal

2Department of Surgery, Janaki Medical College Teaching Hospital, Janakpurdham, Nepal

${ }^{3}$ Nepal Medical College Teaching Hospital, Jorpati, Kathmandu, Nepal

\begin{abstract}
Background and Objectives: Lamotrigine is a "second generation" anti-epileptic drug (AED) approved by the Food and Drug Administration (FDA) and is the first FDA-approved therapy after Lithium for maintenance treatment of bipolar I disorder. It crosses the placenta easily indicating that the maternal treatment leads to a considerable fetal exposure. This study is planned to study the morphological and histological changes induced by Lamotrigine in the fetal rat brain.

Material and Methods: The morphological effect of lamotrigine on fetal rat brain was studied after giving four times its recommended therapeutic dose to 12 pregnant rats and placebo to 6 control rats during the period of organogenesis. The rats were sacrificed on the twentieth day of pregnancy. Body weight, body length, brain weight, brain volume, histological examination of the cerebral cortex and ventricular size of all the delivered fetuses were studied. Non-parametric Mann-Whitney test was used to compare the data.

Results: There was no significant difference in mean body weight, mean body length, mean brain weight and mean brain volume in control and experimental rat fetuses. However one lamotrigine exposed rat fetus had exencephalic malformation and its histological study of the cerebral cortex revealed ill defined plexiform layer and dilated lateral ventricle.

Conclusion: Probability that lamotrigine produces congenital malformation in fetal rats, when
\end{abstract} used during pregnancy, is low.

Key words: AEP, Lamotrigine, congenital malformation, fetus, histological examination

\section{INTRODUCTION}

The risk of congenital malformations ranges from $4-10 \%$ following monotherapy treatment with older, "first generation" Antiepileptic drugs (AEDs) [1]. This is a 2- to 3-fold increased risk It compared to the general population. Lamotrigine, a "second generation" AED was introduced in the mid 1990's. was approved by the Food and Drug Administration (FDA) for use 
as anticonvulsant in USA since 2004 [2, 3]. It is the first FDA-approved therapy after Lithium for maintenance treatment of bipolar I disorder [2,4]. It crosses the placenta easily and rapidly, indicating that the maternal treatment leads to a considerable fetal exposure $[5,6]$. The objective of the study is to study the morphological and histological changes induced by lamotrigine in the fetal rat brain.

\section{MATERIAL AND METHODS}

Twenty Albino Wistar rats with positive vaginal smear for sperm were involved in the study. Fourteen (experimental) rats were given $1.5 \mathrm{mg}$ of lamotrigine, which corresponds to four times the therapeutic dose in human, on the $9^{\text {th }}, 10$ th, and $11^{\text {th }}$ days of pregnancy via gastric intubation. Six (control) rats were given placebo. The rats were sacrificed on the 20th day of pregnancy (one day prior to the expected day of delivery) to deliver fetal rats. Two rats in the experimental group had no pregnancy and were excluded from the study. All the fetuses (60 experimental and 30 controls) were examined for any congenital anomalies and their weight and body length were recorded. Their brains were removed meticulously and the weight and volume were recorded. For the histological studies the brains were fixed by in vivo perfusion technique. Histological preparations of standard thickness were made from different parts of the brains including the cerebral cortex and lateral ventricles using microtome and stained in Haematoxylin - eosin and were studied under various magnifications. The variables were expressed in terms of mean \pm standard deviation. As the data were not homogenously distributed, non-parametric test such as Mann-Whitney U test was used to analyze data.

\section{RESULTS}

With 95 percent confidence interval there were no significant differences in mean body weight, mean body length, mean bra-in weight and mean brain volume in control and experimental fetuses (Table 1). One lamotrigine exposed rat fetus had a well defined, dark brown swelling over the parieto-occipital region and the cervicothoracic junction. The histological study of the cerebral cortex of this fetus revealed relatively less clearly defined plexiform layer (figure 1). Its lateral ventricles were also dilated (figure2).

Table 1: Comparision of various parameters in control and experimental group
\begin{tabular}{|l|l|l|l|}
\hline Parameter & Control & Experimental & p-value \\
\hline No of successful deliveries & 6 & 12 & \\
\hline Number of fetuses per rat & 5 (range, 3-7) & 5 (range, $3-8)$ & \\
\hline Total no. of rat fetuses & 30 & 60 & \\
\hline Body weight (gm) (mean \pm SD) & $2.34 \pm 0.34$ & $2.29 \pm 0.25$ & 0.39 \\
\hline Body length (cm) (mean \pm SD) & $2.93 \pm 0.5$ & $2.77 \pm 0.40$ & 0.90 \\
\hline Brain weight (gm) (mean \pm SD) & $0.11 \pm 0.024$ & $0.12 \pm 0.024$ & 0.34 \\
\hline Brain volume (ml) (mean \pm SD) & $0.14 \pm 0.03$ & $0.15 \pm 0.03$ & 0.19 \\
\hline
\end{tabular}

Figure1: A cross section of cerebral cortex of a lamotrigine treated rat fetus shows ill defined plexiform layer

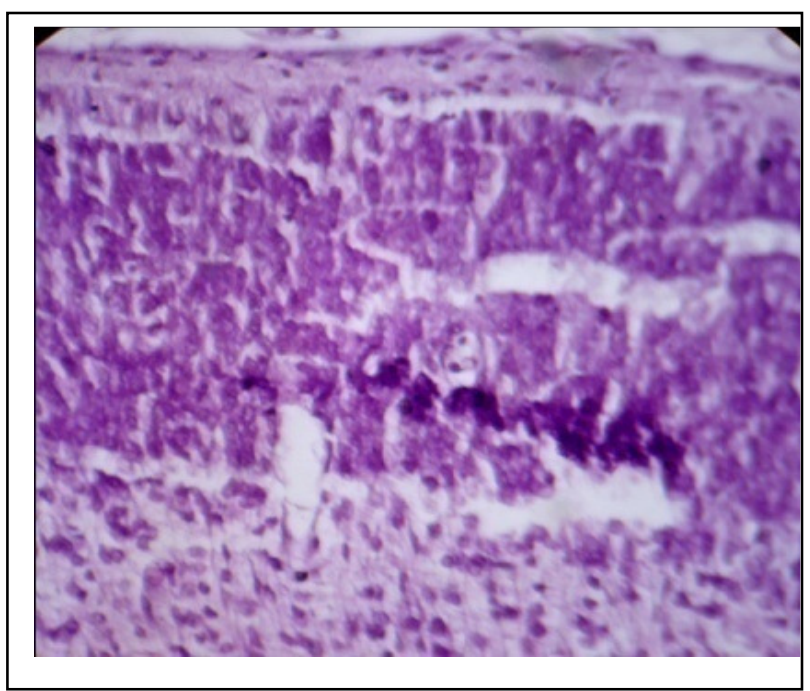


Figure2: Longitudinal sections through the lateral ventricles: $A$, dilated ventricle of a lamotrigine treated rat fetus. B, Normal ventricle of a control fetus

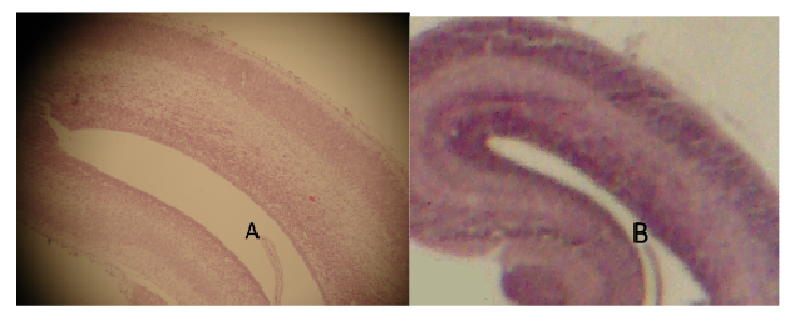

\section{DISCUSSION}

Although use of AEDs during pregnancy is associated with increased risk of congenital malformation in the fetus they cannot be discontinued because of the risk of seizures $[7,8]$. The increased risk was observed mostly with verapamil or carbamazepine monotherapy[9]. Whittle and Brown observed association of neural tube defect in mice with the use of valproic study $[9,10]$. Later on reports on neural tube defects in children after exposure to verapamil was published $[11,12]$.

For second generation AEDs like lamotrigine variable results have been published regarding congenital malformation in experimental animal studies. Marchi et al. demonstrated low birth weight and altered brain structure, which included increased volume and diameter of the cerebral structure, increased density of the subcortical layer, and ventricle dilation in lamotrigine treated rat fetus [13]. In our study also, though not significantly different, offspring of lamotrigine treated rat demonstrated relatively lower mean body weight and body length, and greater mean brain weight and brain volume. One rat fetus had exencepahlic appearance with ill defined plexiform layer and dilated ventricles. The dimensions of the ventricles were not measured because of unavailability of micrometer.

\section{CONCLUSION}

In conclusion, probability that lamotrigine produces congenital malformation in fetal rats,when used produces congenital malformation in fetal rats, when used during pregnancy, is low. However, because of small sample size of the study, the effect in question needs further verification by large scale study.

\section{ACKNOWLEDGEMENT:}

Authors wish to thank department of Anatomy of BPKIHS, Dharan for their support.

\section{REFERENCES}

1. Dolk H, and McElhatton P. Assessing epidemiological evidence for the teratogenic effects of anticonvulsant medications. J Med Genet 2002; 39: 243-244.

2. GlaxoSmithKline. Lamictal: First medication since Lithium approved for long-term maintenance treatment of bipolar disorder. Press Release 2003, June 23.

3. Center for Drug Evaluation and Research. Electronic orange book: Approved drug products. Washington, DC: U.S. Food and Drug Administration. Accessed on April 01, 2005.

4. Bowden CL, Mitchell P, and Suppes T. Lamotrigine in the treatment of bipolar depression. European Neuropsychopharmacology 1999; 9: S113-S117.

5. Rambeck B, Kurlemann G, Stodieck SR, May TW, and Jurgens U. Concentrations of lamotrigine in a mother on lamotrigine treatment and her newborn child. Eur J Clin Pharmacol 1997; 51: 481-484.

6. Myllynen PK, Pienimaki PK, and Vahakangas K H. Transplacental passage of lamotrigine in a human placental perfusion system in vitro and in maternal and cord blood in vivo. Eur J Clin Pharmacol 2003; 58: 677-682.

7. Yerby MS. Problem and management of the pregnant women with epilepsy. Epilepsia 1987; 28: 29-36.

8. Janz D. Anti-epileptic drugs and pregnancy: altered utilization patterns and teratogenesis. Epilepsia 1982; 23(suppl 1): 5343.

9. Brown NA, Kao J, and Fahro S. Teratogenic potential of valproic acid. Lancet 1980; 1: 66\&1.

10. Whittle BA. Pre-clinical teratological studies on sodium valproate (Epilim) and other anticonvulsants. In: Legg NJ, ed. Clinical and pharmacological aspects of sodium valproate in treatment of epilepsy. Kent: Turnbridge Wells, MCS Consultants, 1976; 105-10.

11. Mastroiacovo P, Bertollini R, Morandini S, and Segni G. Maternal epilepsy, valproate exposure, and birth defects. Lancet 1983; 2: 1499. 
Janaki Medical College Journal of Medical Sciences (2013) Vol. 1 (1):26-29

12. Lindhout D, and Schmidt D. In-utero exposure to valproate and neural tube defects. Lancet 1986;1: 1392-3.

13. Marchi NSA, Azoubel R, and Tognola WA. Teratogenic effects of lamotrigine on rat fetal brain. Arq Neuropsiquiatr 2001; 59(2-B): 362-364. 